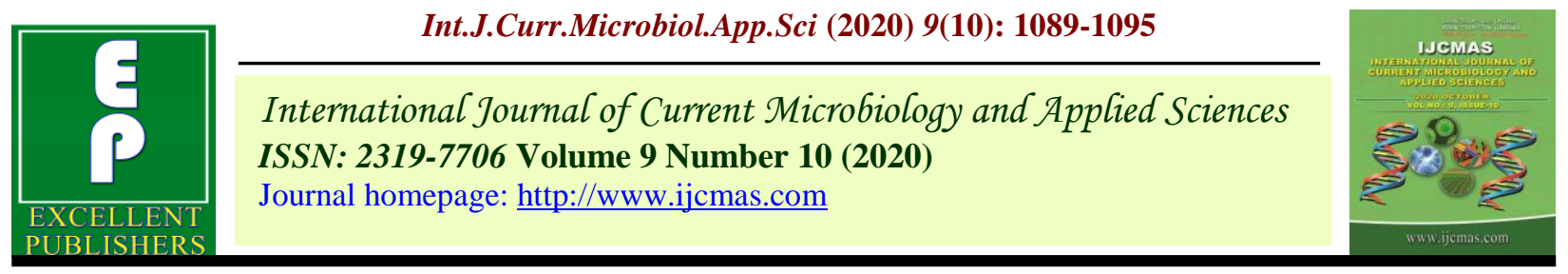

Original Research Article

https://doi.org/10.20546/ijcmas.2020.910.130

\title{
Effect of Quercetin Supplementation on Functional Membrane Integrity of Surti Buck Semen Preserved at Refrigerated Temperature
}

\author{
W.V. Diniz*, L.C. Modi, N.F. Chaudhari and M.A. Pandor
}

Department of Veterinary Gynaecology and Obstetrics, College of Veterinary Science and Animal Husbandry, Navsari Agricultural University, Navsari, Gujarat-396 450, India

*Corresponding author

\section{A B S T R A C T}

Keywords

Antioxidant, Quercetin, Buck semen, Refrigerated temperature

\section{Article Info}

Accepted:

10 September 2020

Available Online:

10 October 2020
A study was conducted to examine antioxidant effect of quercetin in tris egg yolk citrate extender on chilling quality of Surti buck semen. Total 72 semen ejaculates were collected from four Surti buck (18 ejaculate/buck) twice in a week by artificial vagina method. Semen samples were diluted with Tris egg yolk citrate extender and different quercetin concentration viz. C-0 $\mu \mathrm{M}$, T1-15 $\mu \mathrm{M}$, T2-25 $\mu \mathrm{M}$, T3-50 $\mu \mathrm{M}$, T4-75 $\mu \mathrm{M}$, T5-100 $\mu \mathrm{M}$ and stored at refrigerated temperature $\left(4-5^{\circ} \mathrm{C}\right)$. Evaluation of semen parameters was done at $0,24,36$ and 48 hours. The result showed that functional membrane integrity was well maintained at $15 \mu \mathrm{M}$ quercetin in tris egg yolk citrate extended buck semen maintained at refrigerated temperature up to 48 hours.

\section{Introduction}

Goats (Capra hircus) are one of the oldest domesticated species and one among the economically important livestock in India. Considering the poor production potential of goat, the need for genetic improvement via implementation of Artificial Insemination (AI) from superior sires through semen preservation is crucially required. Goat semen can be preserved either at room temperature temporarily, refrigerated temperature for 2448 hours (Ferdinand et al., 2012) or cryopreserved (Beltran et al., 2013) for long term storage. In mammals, sperm protection against oxidative stress is provided mainly by seminal plasma which contains many antioxidants (Zini et al., 2002), but, the protective capacity of endogenous antioxidants may be insufficient to prevent peroxidative damage during storage (Aurich et al., 1997). Therefore, the harmful action of the free radicals can be blocked by exogenous antioxidant substances (Kumaran and Karunakaran, 2006). Natural most widely distributed dietary polyphenolic compounds antioxidant is quercetin, a non-enzymatic antioxidant (Nogueira et al., 2013). 
Supplementation of semen extender with quercetin has been reported to have beneficial antioxidant properties on post-thaw characteristics in sperm cells of bulls (Tvrda et al., 2016), rams (Silva et al., 2012) and bucks (Silva et al., 2016). A functional membrane is requisite for the fertilizing ability of spermatozoa, as it plays an integral role in sperm capacitation, acrosome reaction, and binding of the spermatozoon to the egg surface (Ramu and Jeyendran, 2013). The hypo-osmotic swelling test (HOST) evaluates the functional integrity of the sperm's plasma membrane and also serves as a useful indicator of fertility potential of sperm (Ramu and Jeyendran, 2013).

\section{Materials and Methods}

\section{Semen collection}

Total four apparently healthy Surti bucks above 1 years of age maintained under All India Coordinated Research Project (AICRP) on Goat at Livestock Research Station, Navsari Agricultural University, Navsari were selected. The selected bucks were housed in a common covered pen and managed under uniform managemental and feeding conditions. The animals were allowed to graze between 2:30 PM to 4:30 PM and fed with good quality fodder ad lib. along with $500 \mathrm{~g}$ of concentrate per animal per day. After completion of the training period, semen was collected twice a week from each buck by artificial vagina up to 9 weeks .Total 72 semen ejaculates were collected. Semen was collected from all the selected bucks twice in a week at early morning between 6.00 am to 8.00 am using eight inch artificial vagina (AV) with 40 to $42^{\circ}$ Cinner temperature and sufficient pressure.

\section{Preparation of quercetin}

To prepare stock solution $(1 \mathrm{mg} / \mathrm{ml}), 20 \mathrm{mg}$ of quercetin hydrate (Sigma-Aldrich, St.Louis,
USA) was dissolved in $200 \mu \mathrm{l}$ of $1 \mathrm{M} \mathrm{NaOH}$ with the help of vertex mixture. Thereafter, 18 $\mathrm{ml}$ of Mili Q water was added and $\mathrm{pH}$ of solution was adjusted to 8.0 with $70 \%$ orthophosphoric acid. Finally, make volume to $20 \mathrm{ml}$ by adding Mili Q water to get stock solution $(1 \mathrm{mg} / \mathrm{ml})$ and stored at refrigerated temperature.To prepare $500 \mu \mathrm{M}$ of working solution of $1 \mathrm{ml}, 150 \mu \mathrm{l}$ of stock solution was diluted with $850 \mu$ l of Mili- Q water.

\section{Preparation of tris egg yolk citrate diluter with different concentrations of Quercetin}

The TEYC diluter was prepared on the day of experiment by adding $20 \%$ egg yolk in Triscitric acid-fructose buffer in sterile flask. The mixture was thoroughly mixed with vigorous shaking of flask for five minutes followed by centrifugation for 4 minutes at $3000 \mathrm{rpm}$ in centrifuge machine and the supernatant from each tube was obtained carefully in a sterile glass bottle.Afterward the extender was supplemented with one of the quercetin concentrations [0 $\mu \mathrm{M}$ (control), $15 \mu \mathrm{M}$ (T1), $25 \mu \mathrm{M}$ (T2), $50 \mu \mathrm{M}$ (T3), $75 \mu \mathrm{M}$ (T4) and $100 \mu \mathrm{M}(\mathrm{T} 5)]$ and the observed $\mathrm{pH}$ was 6.66.8

\section{Experimental groups}

Immediately after semen collection, the samples were pooled. The experiment was repeated eighteen times. Only semen samples with $\geq 70 \%$ motility were considered for further processing. The pooled semen was divided into six aliquots and each aliquot was diluted with extender containing Tris-egg yolk citrate diluter with $0 \mu \mathrm{M}$ (control), 15 $\mu \mathrm{M}$ (T1), $25 \mu \mathrm{M}$ (T2), $50 \mu \mathrm{M}$ (T3), $75 \mu \mathrm{M}$ (T4) and $100 \mu \mathrm{M}$ (T5) quercetin separately to a final concentration of $200 \times 10^{6} \mathrm{sperm} / \mathrm{ml}$. After grouping, the semen samples were examined for functional membrane integrity at 0 hour and periodically up to 48 hours for post-chilled functional membrane integrity at 24, 36 and 48 hours. 
Evaluation of functional membrane integrity

To evaluate the functional membrane integrity of spermatozoa, Hypo Osmotic Swelling Test (HOST) was determined by mixing $0.1 \mathrm{ml}$ of diluted semen with $1.0 \mathrm{ml}$ of hypo-osmotic solution and incubated at $37^{\circ} \mathrm{C}$ for 30 minutes. To ascertain the percentage of functional membrane integrity of spermatozoa, smear was prepared on pre-warmed clean glass slide by gentle mixing of a drop of diluted sample with a drop of eosin-nigrosin stain. Total 200 spermatozoa were counted in different fields and percentage of spermatozoa exhibiting tail curling (reacted) was calculated by following formula.

Reacted sperm $(\%)=$

$$
\frac{\text { No. of HOS reacted sperms }}{\text { Total no.of sperm counted }} \times 100
$$

\section{Statistical analysis}

The data pertaining to various aspects were suitably tabulated and analysed using R-3.3.2 software. The differences among the parameter means were performed using appropriate statistical methods viz., ANOVA, DNMRT (Duncan's New Multiple Range Test). The mean differences were considered significant at $\mathrm{p}<0.05$ and $\mathrm{p}<0.01$.

\section{Results and Discussion}

The Functional Membrane Integrity (\%) at 0 hour differed non-significantly between control $(65.33 \pm 0.90), \mathrm{T} 1 \quad(64.72 \pm 0.85)$, T2 (64.33 \pm 0.88$), \mathrm{T} 3(64.61 \pm 0.90)$ and T4 (65.50 $\pm 1.07)$ and T5 (64.94 \pm 0.81$)$ groups.

Similarly, Functional Membrane Integrity (\%) at 24 hours differed non-significantly between control (61.61 \pm 0.78$)$, T1 (61.56 \pm 0.88$)$, T2 (60.11 \pm 0.69$), \mathrm{T} 3(59.06 \pm 0.79)$ and T4 (60.00 $\pm 0.98)$ groups, however, T5 $(62.94 \pm 0.81)$ group differed significantly $(\mathrm{p}<0.01)$. At 36 hours, functional membrane integrity $(\%)$ in control $(57.50 \pm 0.99), \mathrm{T} 1 \quad(58.17 \pm 0.78)$, T2 $(56.33 \pm 0.65)$ and $\mathrm{T} 4(56.11 \pm 0.90)$ groups differed non-significantly, whereas, T3 $(53.22 \pm 0.78)$ and $\mathrm{T} 5(51.83 \pm 0.44)$ groups were significantly $(\mathrm{p}<0.01) \quad$ lower as compared to control, T1, T2 and T4 groups. The functional membrane integrity (\%) at 48 hours was significantly $(\mathrm{p}<0.01)$ lower in control (50.78 \pm 0.63$)$ group as compared to T1 $(53.50 \pm 0.76)$ group, and significantly $(p<0.01)$ higher when compared to T5 $(48.44 \pm 0.61)$ group. Furthermore, there were no significant difference between control and T2 (50.67 \pm 0.62$), \mathrm{T} 3(48.89 \pm 0.69)$ and $\mathrm{T} 4$ (51.33 \pm 0.62$)$ groups. Additionally, T1 differed significantly $(\mathrm{p}<0.01)$ as compared to T2, T3, T4 and T5 groups, whereas, T2, T3; T2, T4 and T3, T5 groups differed nonsignificantly with each other.

The corresponding pooled mean of functional membrane integrity (\%)irrespective of treatment and control groups were reduced with increasing preservation time at $0(64.90$ $\pm 0.36)$ hour followed by 24 (60.88 \pm 0.35$), 36$ $(55.53 \pm 0.38)$ and $48(50.60 \pm 0.31)$ hours.

Furthermore, the functional membrane integrity (\%) in control, T1, T2, T3 and T4 groups were significantly $(\mathrm{p}<0.01)$ higher at 0 $(65.33 \pm 0.90, \quad 64.72 \pm 0.85, \quad 64.33 \pm 0.88$, $64.61 \pm 0.90$ and $65.50 \pm 1.07)$ hour as compared to $24(61.61 \pm 0.78,61.56 \pm 0.88$, $60.11 \pm 0.69, \quad 59.06 \pm 0.79$ and $60.00 \pm 0.98)$ hours, $36 \quad(57.50 \pm 0.99, \quad 58.17 \pm 0.78$, $56.33 \pm 0.65, \quad 53.22 \pm 0.78$ and $56.11 \pm 0.90$ ) hours and $48 \quad(50.78 \pm 0.63,53.50 \pm 0.76$, $50.67 \pm 0.62, \quad 48.89 \pm 0.69$ and $51.33 \pm 0.62$ ) hours. Moreover, the functional membrane integrity (\%) at 24, 36 and 48 hours differed significantly $(\mathrm{p}<0.01)$ among each other (Table 1). 
Table.1 Effect of different concentrations of quercetin and storage duration on functional membrane Integrity (\%) of Surti buck semen preserved at refrigerated temperature $(\mathrm{Mean} \pm \mathrm{SE})$

\begin{tabular}{|c|c|c|c|c|c|c|c|}
\hline \multirow[t]{2}{*}{ Groups } & \multicolumn{4}{|c|}{$\begin{array}{l}\text { HOST reacted- spermatozoa }(\%) \\
\qquad(\mathrm{n}=18)\end{array}$} & \multirow{2}{*}{$\begin{array}{c}\text { Overall } \\
(n=72)\end{array}$} & \multirow[t]{2}{*}{ F value } & \multirow[t]{2}{*}{$P$ value } \\
\hline & O hr & $24 \mathrm{hr}$ & $36 \mathrm{hr}$ & $48 \mathrm{hr}$ & & & \\
\hline $\mathbf{C}$ & $65.33 \pm 0.90_{w}$ & $61.61 \pm 0.78_{x}^{b}$ & $57.50 \pm 0.99^{\mathrm{a}} \mathrm{y}$ & $50.78 \pm 0.63^{b c}{ }_{z}$ & $58.81 \pm 0.76^{\mathrm{ab}}$ & $55.59 * *$ & 0.00 \\
\hline $\mathbf{T 1}$ & $64.72 \pm 0.85_{\mathrm{w}}$ & $61.56 \pm 0.88^{b}$ & $58.17 \pm 0.78_{y}^{a}$ & $53.50 \pm 0.76_{z}^{\mathrm{a}}$ & $59.49 \pm 0.64^{\mathrm{a}}$ & $34.34 * *$ & 0.00 \\
\hline $\mathbf{T} 2$ & $64.33 \pm 0.88_{w}$ & $60.11 \pm 0.69^{b}{ }_{x}$ & $56.33 \pm 0.65^{\mathrm{a}} \mathrm{y}$ & $50.67 \pm 0.62^{\mathrm{bc}}{ }_{\mathrm{z}}$ & $57.86 \pm 0.69^{\mathrm{abc}}$ & $65.67 * *$ & 0.00 \\
\hline T3 & $64.61 \pm 0.90_{w}$ & $59.06 \pm 0.79^{b}{ }_{x}$ & $53.22 \pm 0.78^{b} y$ & $48.89 \pm 0.69^{c d}{ }_{z}$ & $56.44 \pm 0.80^{c}$ & $74.69 * *$ & 0.00 \\
\hline T4 & $65.50 \pm 1.07_{\mathrm{w}}$ & $60.00 \pm 0.98_{x}^{b}$ & $56.11 \pm 0.90^{\mathrm{a}} \mathrm{y}$ & $51.33 \pm 0.62^{b}{ }_{z}$ & $58.24 \pm 0.76^{\mathrm{abc}}$ & $43.72 * *$ & 0.00 \\
\hline T5 & $64.94 \pm 0.81_{\mathrm{w}}$ & $62.94 \pm 0.81^{\mathrm{a}}{ }_{\mathrm{w}}$ & $51.83 \pm 0.44^{b}{ }_{x}$ & $48.44 \pm 0.61_{y}^{d}$ & $57.04 \pm 0.90^{b c}$ & $140.82 * *$ & 0.00 \\
\hline $\begin{array}{l}\text { Overall } \\
(n=108)\end{array}$ & $64.90 \pm 0.36_{w}$ & $60.88 \pm 0.35_{x}$ & $55.53 \pm 0.38_{y}$ & $50.60 \pm 0.31_{z}$ & -- & -- & -- \\
\hline F value & 0.42 & $4.37 * *$ & $10.26 * *$ & $7.68 * *$ & -- & -- & -- \\
\hline P value & 0.83 & 0.00 & 0.00 & 0.00 & -- & -- & -- \\
\hline
\end{tabular}

${ }^{\mathrm{a}-\mathrm{d}}$ Means with different superscript within a column (between the groups) differs significantly at $\mathrm{p}<0.05 ; \mathrm{p}<0.01$.

${ }^{\mathrm{w}-\mathrm{z}}$ Means with different subscript between a column (between time intervals) differs significantly at $\mathrm{p}<0.05 ; \mathrm{p}<0.01$.

$* * \mathrm{p}<0.01 ; * \mathrm{p}<0.05$.

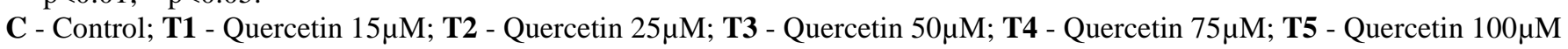


In T5 group, functional membrane integrity (\%) differed non-significantly at 0 (64.94 \pm 0.81$)$ hour and $24(62.94 \pm 0.81)$ hours, whereas, at $36 \quad(51.83 \pm 0.44)$ and 48 $(48.44 \pm 0.61)$ hours there were significantly $(\mathrm{p}<0.01)$ lower HOST reacted sperm percentages as compared to 0 and 24 hours. However, the functional membrane integrity $(\%)$ differed significantly $(\mathrm{p}<0.01)$ between 24,36 and 48 hours.

In this study highest post chilled HOST reacted sperm was observed in T1 group as $58.17 \pm 0.78$ and $53.50 \pm 0.76$ at 36 and 48 hours, respectively, as compared to other groups.

In accordance to our present findings, SeifiJamadi et al., (2017) demonstrated that significantly $(\mathrm{p}<0.05)$ higher freeze-thaw plasma membrane integrity in $10 \mu \mathrm{M}$ (55.00 \pm 1.65$)$ quercetin group when compared with $20 \mu \mathrm{M}(49.60 \pm 1.16)$ quercetin and nonsignificantly higher than control (51.48 \pm 1.69) group. Functional Membrane Integrity in present study remained non-significant between control and $15 \mu \mathrm{M}$ up to 36 hours, although, they differed significantly at 48 hours. Equally, Avdatek et al., (2018) in their study found no significant difference between control and quercetin at $25 \mu \mathrm{g} / \mathrm{ml}$ $(34.37 \pm 1.71)$ group in post-thaw bull semen, however, membrane integrity was marginally reduced at $50 \mu \mathrm{g} / \mathrm{ml}$ and significantly $(\mathrm{p}<0.05)$ reduced at $100 \mu \mathrm{g} / \mathrm{ml}$ quercetin concentration. In another similar study, Silva et al., (2016) found no significant difference among quercetin treated groups when compared to control at 0 and 1 hour, though, plasma membrane integrity was significantly lower $\quad(p<0.05)$ after 1 hour of incubationat $34^{\circ} \mathrm{C}$.

Conflicting to our present data, $100 \mu \mathrm{M}$ quercetin group had significantly $(\mathrm{p}<0.01)$ lower functional membrane integrity than control group. Similarly, Seifi-Jamadi et al., (2016) also observed that $0.1 \mathrm{mM}$ $(42.92 \pm 2.39 \%)$ quercetin was not significantly different than control $(42.91 \pm 0.96 \%)$ groups. But, at higher quercetin concentration $(0.2$ and $0.3 \mathrm{mM})$ sperms were adversely affected. They declared that at higher concentrations a partial prooxidant effect of quercetin on membrane integrity could limit its usage.

In addition, Filho et al., (2017) and Kim et al., (2014) found no significant difference between control and any of the quercetin treatment groups in equine and boar semen, respectively. Thus, similarly to our findings these experiments concluded that quercetin supplementation did not affect the membrane integrity at any concentration.

Furthermore, when quercetin was administered In vivo by Yelumalai et al., (2019), they found that the percentage of HOS tail coiled sperm was highest in normal, non-diabetic rats, which was not affected by quercetin treatment. Similarly, when quercetin was co-administered with $\mathrm{H}_{2} \mathrm{O}_{2}$ at $40 \mu \mathrm{mol}$ quercetin, it gave non-significantly higher result than other groups Ghaniei et al., (2019). They also declared that per cent of sperm membrane functionality of rooster semen was reduced $(p<0.05)$ in a time dependency manner for 0,24 and 48 hours of freezing.

\section{Acknowledgements}

Authors are grateful to Dean, College of Veterinary Science \& AH., Navsari Agricultural University, Navsari; Research Scientist, Livestock Research Station, NAU and all the staff of Department of Gynaecology \& Obstetrics for providing facilities and support to complete the present investigation. 


\section{Conflict of interest statement}

Authors declare that they have no conflict of interest.

\section{References}

Aurich, J. E., Schonherr, U., Hoppe, H. and Aurich, C. (1997). Effects of antioxidants on motility and membrane integrity of chilled- stored stallion semen. Theriogenology, 48: 185-192.

Avdatek, F., Yeni, D., Inanc, M. E., Cil, B., Tuncer, B. P., Turkmen, R. and Tasdemir, U. (2018). Supplementation of quercetin for advanced DNA integrity in bull semen cryopreservation. Andrologia, 50(4): $129-75$.

Beltran, M. A. G., Atabay, E. P., Atabay, E. C., Cruz, E. M., Aquino, F. P. and Cruz, L. C. (2013). Optimized extenders for cryopreservation of buck semen for artificial insemination. Philippine Journal of Veterinary and Animal Sciences, 39(1): 1-10.

Ferdinand, N., Thomas, T. T., Augustave, K., Henry, D. F., Fernand, T. and Etienne, P. T. (2012). Effects of Buck Age, Storage Duration, Storage Temperature and Diluent on Fresh West African Dwarf Buck Semen. Journal of Reproduction and Infertility, 3(3): 5866.

Filho, J. S., Corcini, C. D., Santos, F. C. C. D., Anciuti, A. N., Gatti, N. L. S., Anastacio, E. and Junior, A. S. V. (2017). Quercetin in Equine Frozen Semen. CryoLetters, 38(4): 299-304.

Ghaniei, A., Eslami, M., ZadehHashem, E., Rezapour, R. and Talebi, A. (2019). Quercetin attenuates $\mathrm{H}_{2} \mathrm{O}_{2}$ - induced toxicity of rooster semen during liquid storage at $4^{\circ}$ C. Journal of animal physiology and animal nutrition, 103(3): 713-722
Kim, T. H., Yuh, I. S., Park, I. C., Cheong, H. T., Kim, J. T., Park, C. K. and Yang, B. K. (2014). Effects of Quercetin and Genistein on Boar Sperm Characteristics and Porcine IVF Embyo Developments. Journal of Embryo Transfer, 29(2): 141-148.

Kumaran, A. and Karunakaran, R. J. (2006). Antioxidant and free radical scavenging activity of an aqueous extract of Coleus aromaticus. Food Chemistry, 97: 109114.

Nogueira, B. G., Bitencourt, J. L., Sampaio, B. F. B., Bender, E. S. C., Costa e Silva, E. V. and Zuccari, C. E. S. N. (2013). Rev 48 Electron Vet. 15: 1-15.

Ramu, S. and Jeyendran, R. S. (2013). The hypo-osmotic swelling test for evaluation of sperm membrane integrity. Spermatogenesis (pp. 21-25). Humana Press, Totowa, NJ.

Seifi-Jamadi, A., Kohram, H., Shahneh, A. Z., Ansari, M. and Macías-García, B. (2016). Quercetin ameliorate motility in frozen-thawed turkmen stallions sperm. Journal of Equine Veterinary Science, 45: 73-77.

Seifi-Jamadi, A., Ahmad, E., Ansari, M. and Kohram, H. (2017). Antioxidant effect of quercetin in an extender containing DMA or glycerol on freezing capacity of goat semen. Cryobiology, 75: 15-20.

Silva, E. C., Cajueiro, J. F., Silva, S. V., Soares, P. C. and Guerra, M. M. (2012). Effect of antioxidants resveratrol and quercetin on in vitro evaluation of frozen ram sperm. Theriogenology, 77(8): 1722-1726.

Silva, E. C. B., Arruda, L. C. P., Silva, S. V., Souza, H. M. and Guerra, M. M. P. (2016). High resveratrol or quercetin concentrations reduce the oscillation index of frozen goat semen. Arquivo Brasileiro de Medicina Veterinaria e Zootecnia, 68(5): 1237-1243.

Tvrda, E., Tusimova, E., Kovacik, A., Paal, 
D., Libova, L. and Lukac, N. (2016). Protective effects of quercetin on selected oxidative biomarkers in bovine spermatozoa subjected to ferrous ascorbate. Reproduction in Domestic Animals, 51: 524-537.

Yelumalai, S., Giribabu, N., Kamarulzaman Karim, S. Z. O. and Salleh, N. B. (2019). In vivo administration of quercetin ameliorates sperm oxidative stress, inflammation, preserves sperm morphology and functions in streptozotocin-nicotinamide induced adult male diabetic rats. Archives of Medical Science: AMS, 15(1): 240.

Zini, A., Fischer, M., Mak, V., Phang, D. and Jarvi, K. (2002). Catalase-like and superoxide dismutase-like activities in human seminal plasma. Urological Research, 30(5): 321-323.

\section{How to cite this article:}

Diniz, W.V., L.C. Modi, N.F. Chaudhari and Pandor, M.A. 2020. Effect of Quercetin Supplementation on Functional Membrane Integrity of Surti Buck Semen Preserved at Refrigerated Temperature. Int.J.Curr.Microbiol.App.Sci. 9(10): 1089-1095.

doi: https://doi.org/10.20546/ijcmas.2020.910.130 